\title{
MATERIAL SELECTION AS COOPERATIVE PROCESS: A FRAMEWORK PROPOSAL FOR A CHANGING ECONOMY
}

\author{
Papile, Flavia (1); \\ Del Curto, Barbara (2);
}

Coccia, Andrea (3)

1: Design Department of Politecnico di Milano;

2: Department of Chemistry, Materials and Chemical Engineering "Giulio Natta" of Politecnico di Milano;

3: Innovation Manager at Faber S.p.A.

\begin{abstract}
In current era of Anthropocene, human activities and their consequences on Earth ecosystems are under the lens of scientific research. Researchers in every field of study are trying to find alternatives to promote sustainable development. So it is for design, where researchers exploiting the problemframing and problem-solving nature of the design discipline itself, trying to find new methodologies and tools to enhance sustainable development. One of the most important tasks in the design for a sustainable production is focused on material selection. In this paper, authors will present a reflection upon material selection methods and an overview of existing material repositories. Traditionally, material selection is usually attributed to designers or technical professionals but nowadays information concurring in materials selection became a complex task to manage. Therefore, authors propose a case study concerning information management upon materials and their selection presented in a new possible approach: material selection as a collaborative task between several departments of an industrial company, to promote an aware information management activity upon materials.
\end{abstract}

Keywords: Material selection, Decision making, Industrial design, Information management, Sustainability

\section{Contact:}

Papile, Flavia

Politecnico di Milano

Design

Italy

flavia.papile@polimi.it 


\section{INTRODUCTION}

In current times, where Climate Change consequences and the reconnaissance of the Anthropocene era (Crutzen \& Stoermer, 2000) are demanding for the adoption of a new, profound reflection on human activity and its impacts on the entire Ecosystem, design research and scientific research in general are trying to provide some new instruments and methodologies to promote radical changes in economical, societal and socio-technical levels.

This urgency has been interpreted differently among years, commonly referring to the term of "sustainable development"(WCED, 1987). When speaking about "sustainability", three main dimensions must be involved in the discussion (Vezzoli and Srinivasan, 2014): environment, society and economy, also known as the Triple Bottom Line (TBL) (Elkington, 1994).

In a socio-economical point of view, those models have been interpreted with the theorisation of new economical models: the "Green Economy", the "Blue Economy" (Pauli, 2018) or even the most recent "Circular Economy" model (Ellen MacArthur Foundation, 2017) are probably the most famous ones.

If we go through all the new models proposing sustainable development based on the TBL we can find several common points on which all of those models work upon. Among them, the theme of resources depletion is a recurring one. The use of natural resources is at the basis of the sustainable development definition and consequently a central topic in the diverse guidelines for sustainable development that we can find in literature (Figure 1).

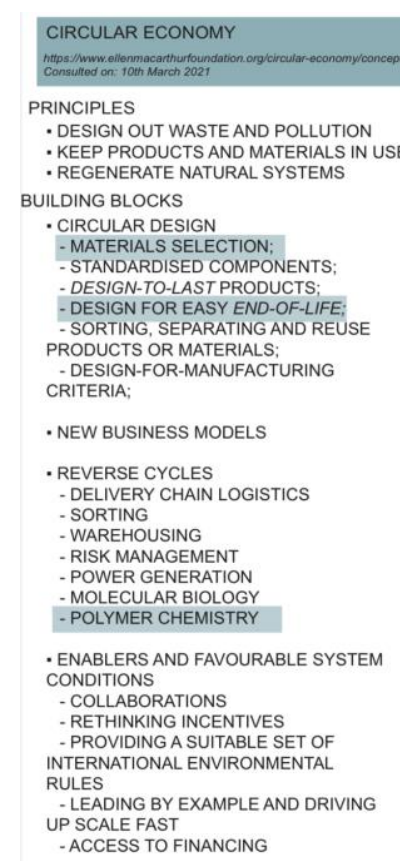

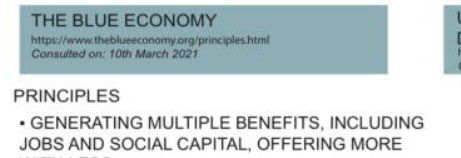

- GENERATING MULTIPLE BENEFITS, INCLUDING JOBS AND SOCIAL CAPITAL, OFFERING MORE - SOLUTIONS BASED ON PHYSICS. - QUESTION ANY RESOURCE REGARDING ITS NECESSITY FOR PRODUCTION. - NATURAL SYSTEMS CASCADE NUTRIENTS, MATTER AND ENERGY - WEALTH MEANS DIVERSITY. INDUSTRIAL STANDARDIZATION IS THE CONTRARY NATURE IS CONTRARY TO MONOPOLIZATION. GRAVITY IS MAIN SOURCE OF ENERGY, SOLAR ENERGY IS THE SECOND RENEWABLE FUEL - WATER IS THE PRIMARY SOLVENT (NO COMPLEX, CHEMICAL, TOXIC CATALYSTS, NATURE ONLY WORKS WITH WHAT IS LOCALIY AVAILABLE.

- NATURE RESPONDS TO BASIC NEEDS AND THEN EVOLVES FROM SUFFICIENCY TO ABUNDANCE. - NATURAL SYSTEMS ARE NON-LINEAR. IN NATURE EVERYTHING IS BIODEGRADABLE. IT IS JUST A MATTER OF TIME. IN NATURAL SYSTEMS EVERYTHING CONNECTEDA

- IN NATURE WATER, AIR, AND SOIL ARE THE COMMONS. FREE AND ABUNDANT

- IN NATURE ONE PROCESS GENERATES

MULTIPLE BENEFITS.

- NATURAL SYSTEMS SHARE RISKS. ANY RISK IS A MOTIVATOR FOR INNOVATIONS

- NATURE IS EFFICIENT. SO SUSTAINABLE

BUSINESS MAXIMIZES USE OF AVAILABLE MATIT PRICE FOR THE CONSUMER NATURE SEARCHES FORALL INVOLUCRATED ELEMENTS

- IN NATURE PROBLEMS ARE OPPORTUNITIES. - ONE NATURAL INNOVATION CARRIES VARIOU BENEFITS FOR ALL.

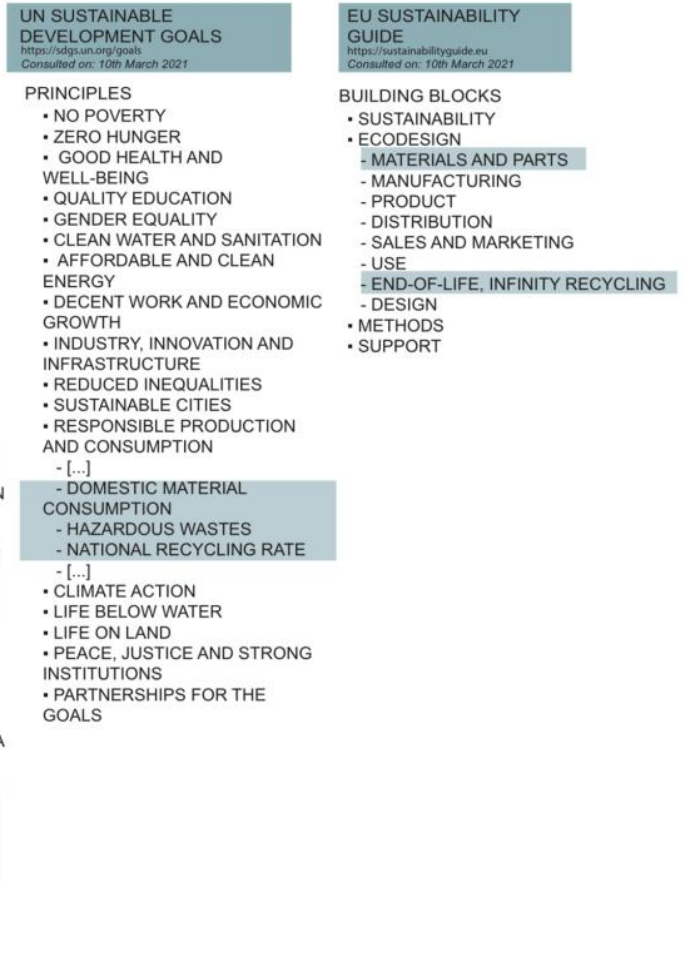

Figure 1. Enlightening how considerations upon materials are embedded in several sustainable development models. Personal elaboration based on: MacArthur,2017; Pauli, 2018; https://sdgs.un.org/goals; https://sustainabilityguide.eu/ecodesign/

After stating the centrality of the materials information management, authors in this paper will try to understand if current industrial system is updated to forward an easy sustainable development oriented material selection process. Starting from a reflection upon relevant information for material selection, it will follow an investigation of existing tools to empower the selection process and a final analysis of the process itself into an industrial company. The objective of the work is to map the material selection process into existing contexts, maintaining and promoting a new systemic perspective, to understand if the classical material selection methods still supports new sustainable production models. 


\section{MATERIALS AND THEIR DIMENSIONS}

Material selection is not a novel process for design research. Materials are at the basis of man-made artefacts and they are representative of human socio-cultural and technical evolution over time since the beginning of human history (du Gay, Smart Martin, Miller, \& Spyer, 1999). In this perspective, the selection of the prime matter from which "artefacts are made of" gains a certain relevance. From the very beginning of industrial production and for many years, materials have been mainly perceived as constituents of physical artefacts (Cornish, 1987). But over time, an increasing number of characteristics and attributes have been analysed and considered relevant for the material selection process, moving from a functional to an hedonic and then an ethical level, as summarised in Figure 2 (Allione, De Giorgi, Lerma, \& Petruccelli, 2012; Ashby \& Johnson, 2014; Karana, Hekkert, \& Kandachar, 2008; van Kesteren, 2008).

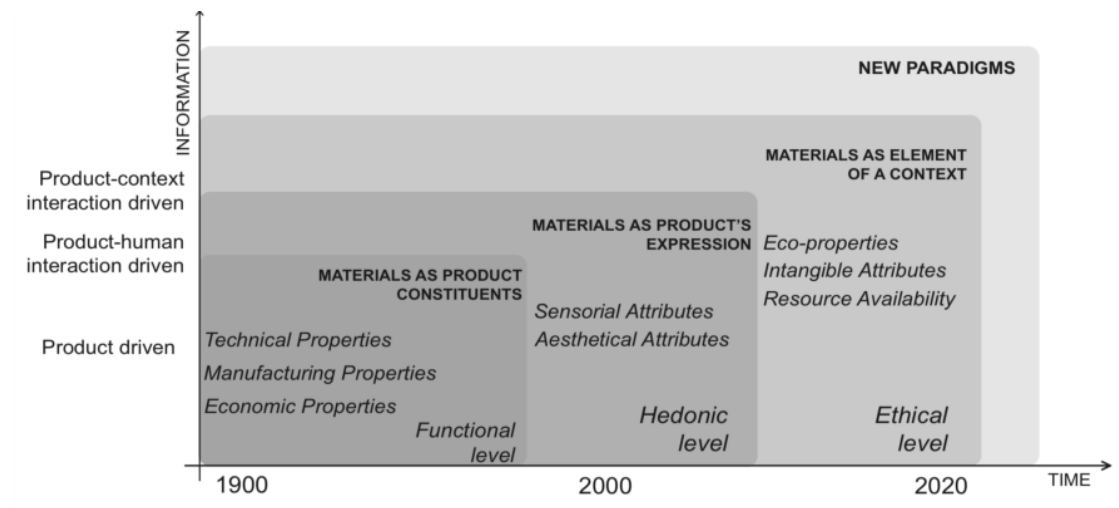

Figure 2. Graphic elaboration that summarises the evolution over time of material properties and characteristics considered in product design material selection activity.

In the last 20 years, not only characteristics and attributes related to materials evolved. In fact, material science and chemistry advancements lead to the discovery and synthesis of new materials. From an estimation made in 2013 (Ashby, Shercliff, \& Cebon, 2013) designers, engineers and artists dispose of more than 160,000 different materials between which making a choice. The increasing number of information concurring in materials selection plus the vast number of materials available, led practitioners to face a complex decision-making activity, an "iperscelta" (Manzini, 1989).

To manage this "iperscelta", several methodologies have been theorised: first in engineering field, as resumed in Figure 3 (Allwood, Ashby, Gutowski, \& Worrell, 2011, 2013; Braungart et al., 2007; Jahan, Ismail, Sapuan, \& Mustapha, 2010); but then also in the design field (Akin \& Pedgley, 2014; Karana, Hekkert, \& Kandachar, 2010; Wilkes \& Miodownik, 2018; Wilkes et al., 2014). In all the methodologies reviewed in literature, material selection process is commonly attributed to engineers, technical professionals, or designers or, eventually, in mutual collaboration between them.

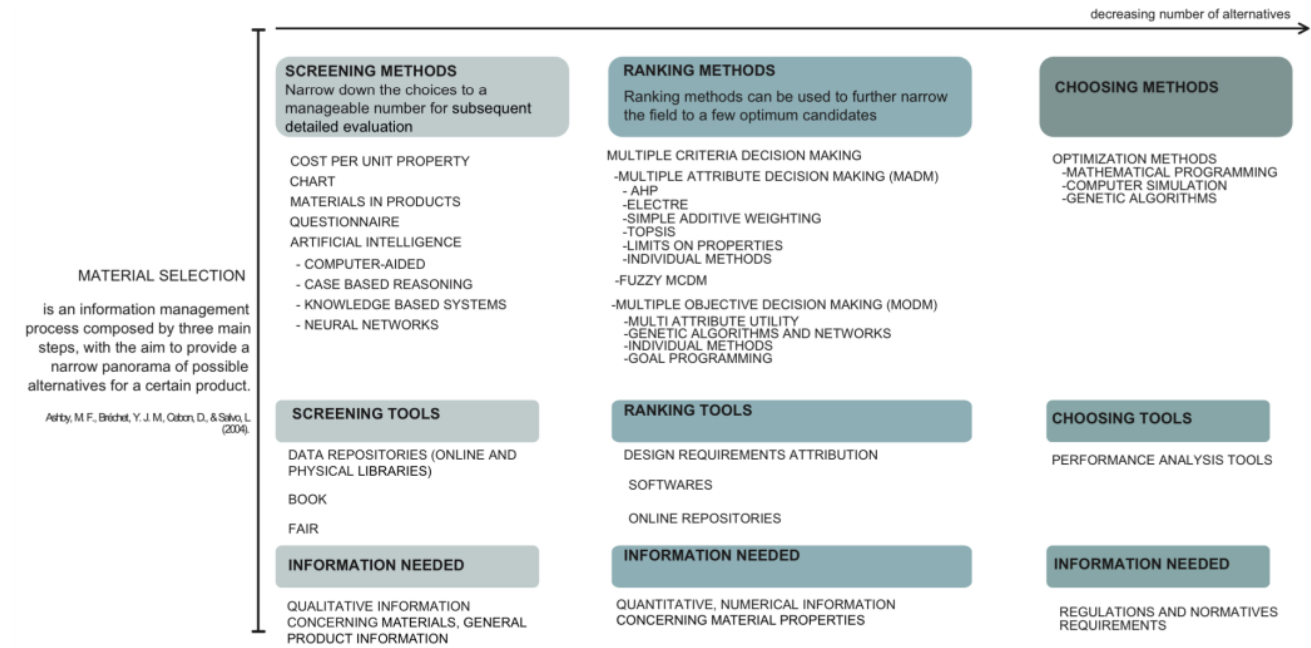

Figure 3. Material selection main steps coupled with existing methodologies and tools already developed in literature. Author's personal elaboration based on: Ashby, Bréchet, Cebon, \& Salvo, 2004; Jahan et al., 2010; Ramalhete et al., 2010. 
From the research in both engineering and design fields, several tools have been developed over time to improve the material selection activity. Through a systematic analysis of 35 different repositories, inspired by previous analytical works (Ramalhete, Senos, \& Aguiar, 2010), it has been possible to enlighten that material repositories are already promoting new sustainable materials. In addiction, in order to systematise the typology of information provided by each tool and build a useful mapping of existing material repositories, authors categorised the 35 sources for their addressing user and for their main utility in relationship with the state-of-project development. This systematic analysis has been conduced following the criteria shown in Figure 4, in order to properly map some of the existing tools that can facilitate practitioner's material selection activity.
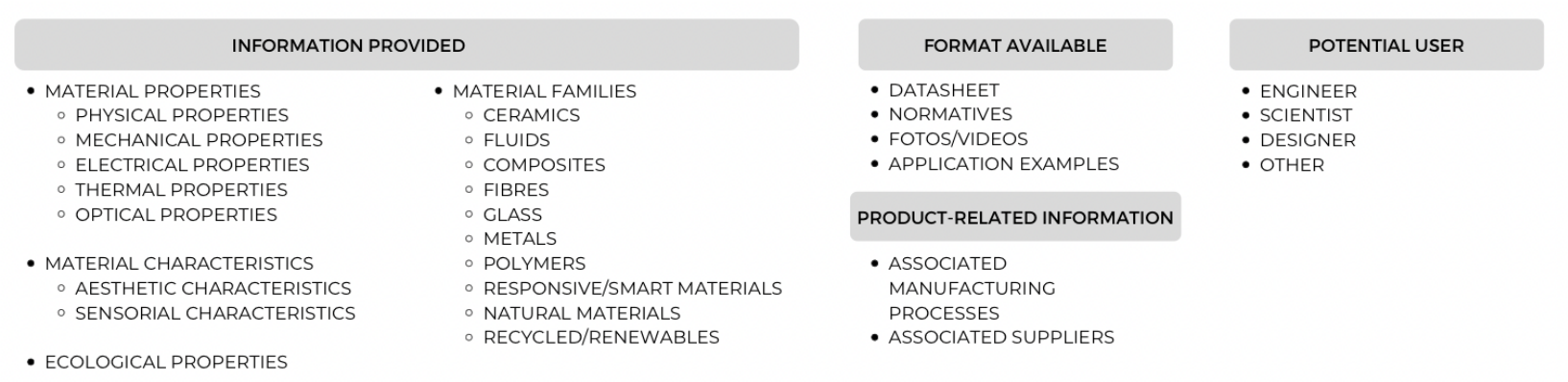

Figure 4. Criteria adopted to analyse existing material repositories for material selection.

At this point, sources between databases, softwares and material libraries have been analysed following the filters listed above and the complete work is reported in the APPENDIX.

The main finding of this critical analysis consists in understanding how the different online repositories could actually be clustered by probable referring professional audience. It is possible to enlighten a multitude of existing tools that already organised and categorised informations upon materials to help professionals in properly collecting information concerning materials. However, it is not always easy to understand if those tools are effectively applied in the industrial context and how much they are effective.

\subsection{Issues in material selection practice: in field research}

In order to better frame the previous statement, a direct feedback from the field was necessary to understand if those tools as well as academic methodologies currently match with the needs and the strict routines of an industrial reality.

\section{A SYSTEMIC PERSPECTIVE FOR MATERIAL SELECTION: FROM A STEP- BASED PROCESS TO AN AGILE ONE}

Information needed by practitioners to improve an efficient material selection activity is nowadays characterised by huge number of interdependencies between the material chosen and all the possible side-effects upon its production, manufacturing, dismissing, recovery and maintenance.

Responding to EU demands ${ }^{1}$ and the current transitional moment, material selection should be a process more fluid, rapid and resilient in order to assess always changing demands for a sustainable production and be able to allow industrial companies to rapidly assess their production according to the societal and environmental demands. In order to do this, material selection should be threaten as a process within a system, in this case, an industrial company. Since a huge number of tools is already present, to verify if material selection activity into an industrial context is a fluid and efficient process, a grounded research in Italian company Faber S.p.A. has been conduced as follows.

\subsection{Observations, unstructured interviews and survey}

A qualitative analysis to figure out how material selection is currently managed by the employees has been pursued towards observations and unstructured interviews to key-role employees in the company. 
In a three-days presence into the headquarters, 9 unstructured interviews have been conduced with different department heads of the company, so that they could provide an overview of the material selection process towards the different product design process steps. Information concerning the activities involved in the product design flow have been collected and some reflections on how the possible introduction of new materials in the workflow may occur have been registered. The unstructured interviews format has been successful in order to maintain a comfortable dialogue with the employees and avoid too narrow questions, leaving them the possibility to explain their main concerns on the topic.

The main insights emerging from the interviews have been the followings: in the dynamic context of an industrial reality, material selection is perceived as a time costing activity and generally it is preferred to go on with already known materials. Moreover, new material application requests are no more confined only into the technical offices, but they can emerge at different steps of the design workflow and be promoted by different industrial departments. In this perspective, all the assumptions taken as starting point in the definition of material selection methodologies in literature seems to not perfectly match the real-life context in this case. Assuming that material selection is a task prevalently executed by a technical department creates turbulences into the workflow, with several rebounds on the technical office in case of material variations. Moreover, expertise coming from other departments makes constraints and suggestions even in technical form. So, the necessity of redefining a lean material selection activity emerges.

This first qualitative analysis was useful to let emerge some consideration upon material selection, but a more detailed survey was necessary to obtain quantitative results concerning the material selection activity and its implications on the whole production flow.

An online form has been created to investigate the following argumentations:

- Who actually manages the material selection task;

- Who should actually manage the material selection task;

- How often new materials are introduced into the workflow;

- If introducing new materials is a useful task;

- If research upon new materials is already embedded into the workflow and if it is perceived as time costing activity.

A panel of 30 employees took part into the survey. The minimum number of necessary answers has been calculated by the Slovin's formula ${ }^{2}$, defining as the referring population all of the employees that had a minimum of 5 years experience in the company, in order to exclude from the survey underexperienced employees and have better quality of the answers.

The online form has been useful to quantify in a univocal way the impressions collected towards the unstructured interviews. The results showed that material selection is currently managed by technical offices, however it is a shared opinion that more than one department should be involved into the task completion. Research on new materials is considered a useful task, but also a time costing activity, generally limited to the design of a new product more than into upgrading existing ones. Also, it was visible from the results that the suggestion of new material introduction necessity derives more from the marketing department than from the R\&D ones.

If some results are emerging in a clear and foregone way, it is also interesting to enlighten the confused pattern that grows on some uncertainties in the answers (e.g. that marketing department is the main promoter of the introduction of new materials in the workflow).

In this perspective, material selection starts to be an activity no more constrained to technical departments only, but refers to several actors towards all the product design process. So what if material selection and, subsequently resource management into an industrial company, could be threaten as a systemic process? In order to verify the appropriateness of this research question, an investigation into a real industrial context followed.

\subsection{Participatory action research}

The focus of this methodology is conducing research by, for and with the people who will take benefits for the research output itself (Bilandzic \& Venable, 2011). It is a methodology flexible

2 Slovin's Formula: $\mathrm{n}=\mathrm{N} /(1+\mathrm{Ne} 2)$ Where: $\mathrm{n}=$ Number of samples, $\mathrm{N}=$ Total population and $\mathrm{e}=$ Error tolerance (level). 
uniquely suited to researching and supporting change. In this perspective, a workshop into the company has been planned to define a possible new approach to material selection process, oriented in managing as much material dimensions as possible, towards a collaborative approach between all the departments. To understand the efficiency of a material selection process threaten as a collaborative task, some baselines to create a common objective were necessary. Stakeholders involvement at this step has been fundamental to collect direct experiential information and promote a collaboration through departments referring employees since the very first step of a new model definition.

To map out the material selection process flow and to enlighten possible spots in the workflow for mutual collaboration between departments, the following focuses have been explored with the employees through several activities:

- Which kind of information is needed by the different departments for the selection of new materials;

- How the information flows between departments in order to pursuit an efficient material selection activity.

The workshop has been undertaken in two half-days timetable with an alternation of oral presentation made by the workshop organisers and collaborative activities. Eleven employees took part into the workshop and were mainly involved in two principal activities:

- Completing a critical analysis matrix upon several suggested online material libraries, in order to understand how the online sources can be used to collect information about new materials;

- Completing a "desiderata schedule", a schedule properly designed by researchers in order to collect information concerning how each department could manage the introduction of a new material and which departments are working in adjacent set-up.

The eleven participants involved in the workshop where representatives of all the different company departments (listed in Figure 5) and the main activities where employees have been involved led to the collection of all the information needed for each department when pursuing a material selection activity and a verification of the utility for scouting in material online repositories to gather filtered materials information from databases.

\section{WORKSHOP RESULTS AND DISCUSSION}

The workshop has been useful to create a collective, reflective moment on the importance of introducing new materials into the workflow and to visualise the implications that a certain material choice can carry in every department. The participation to the workshop activity has been qualitatively high and rich of debate: some interesting insights came up, enlightening that not only an univocal workflow could be supposed for the introduction of new materials, but at least two of them in parallel. Results emerging from the first activity are summarised in Figure 5.

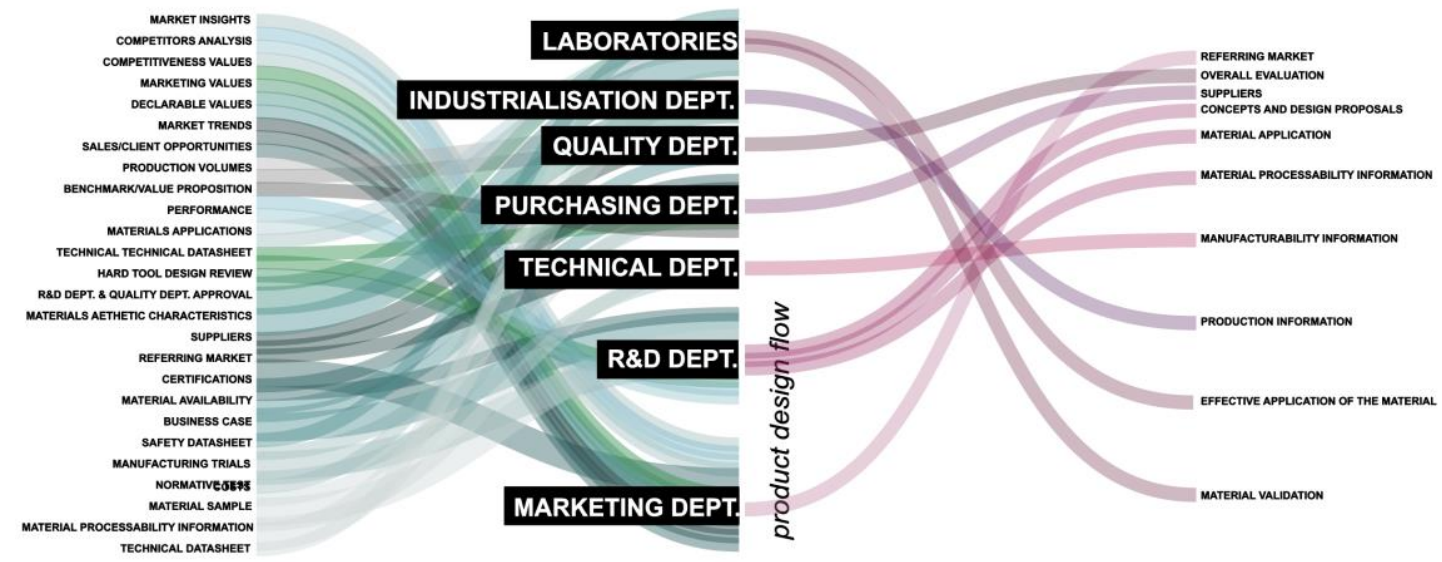

INPUT INFORMATION

REFERRING DEPARTMENT

OUTPUT INFORMATION

Figure 5. Information needed and provided by each department to manage material selection activity in a cooperative way.

By overlapping data obtained by the workshop, some literature concerning the information management of industrial workflows (Browning, Deyst, Eppinger, \& Whitney, 2002; Krishnan \& Ulrich Karl T., 2001; Unger \& Eppinger, 2011) and the three main steps concerning material selection 
activity, a preliminary mapping of the workflow in which material selection task occurs as a collaborative activity is represented in Figure 6.

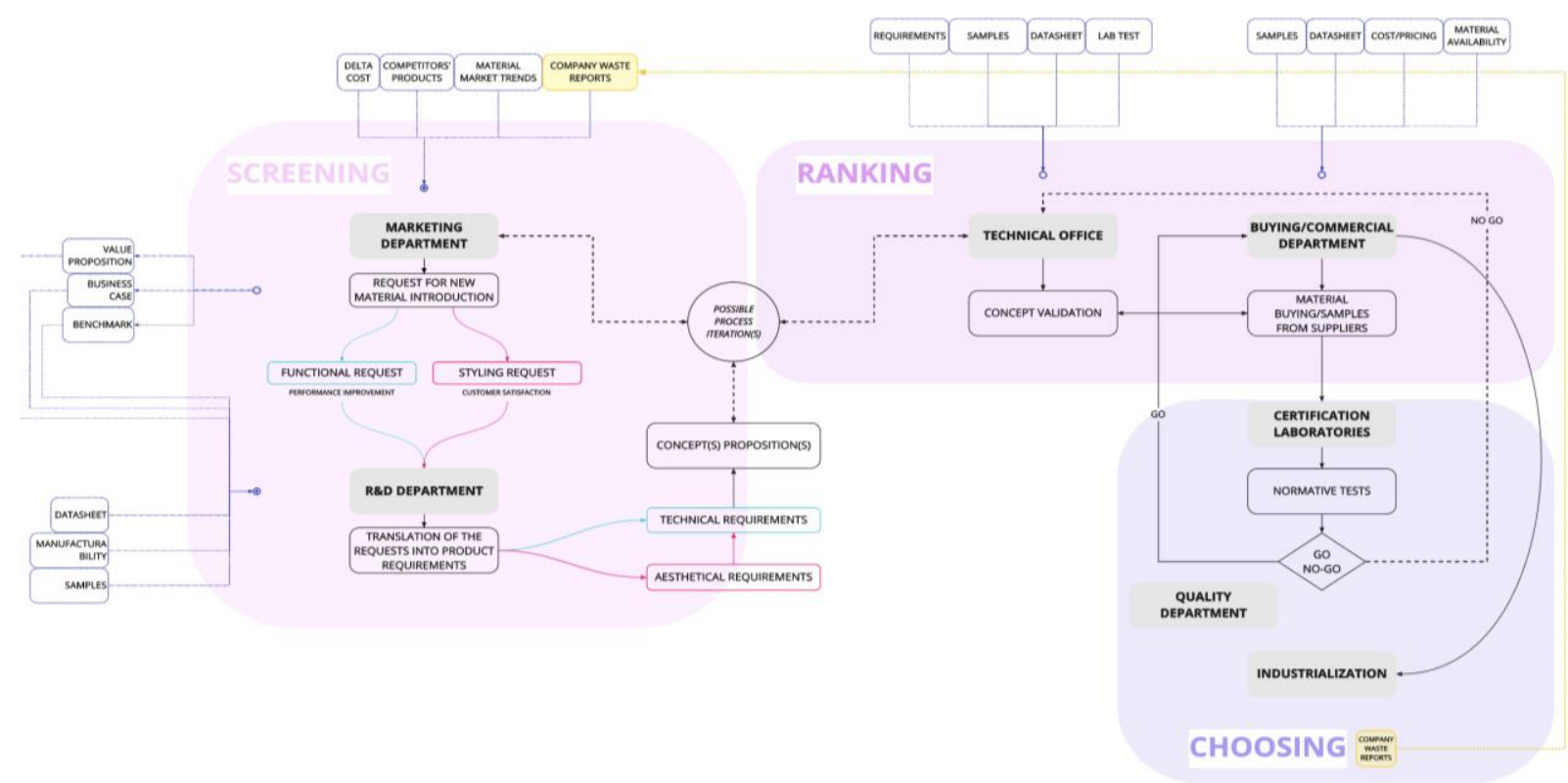

Figure 6. Material selection and its steps overlapped to industrial workflow depicted with the company employees.

Mapping has been a useful methodology to depict in a simple way all the iterations, relationships and information concerning material selection in industrial context. Creating a visual narrative of the whole work and at the same time defining the referring system boundaries (Jones \& Bowes, 2017; Sevaldson, 2011) has been necessary to have a shared focus and completely understanding the interdependencies of a single choice into the entire process. In the presented perspective, material selection needs to be managed in a cooperative way, becoming a transversal process into the workflow. Through the cooperation with the research stakeholders, it has been possible to start dividing in a proper way the information concurring in the material selection activity, trying to include in the process also reflections upon the different material levels (Figure 7).

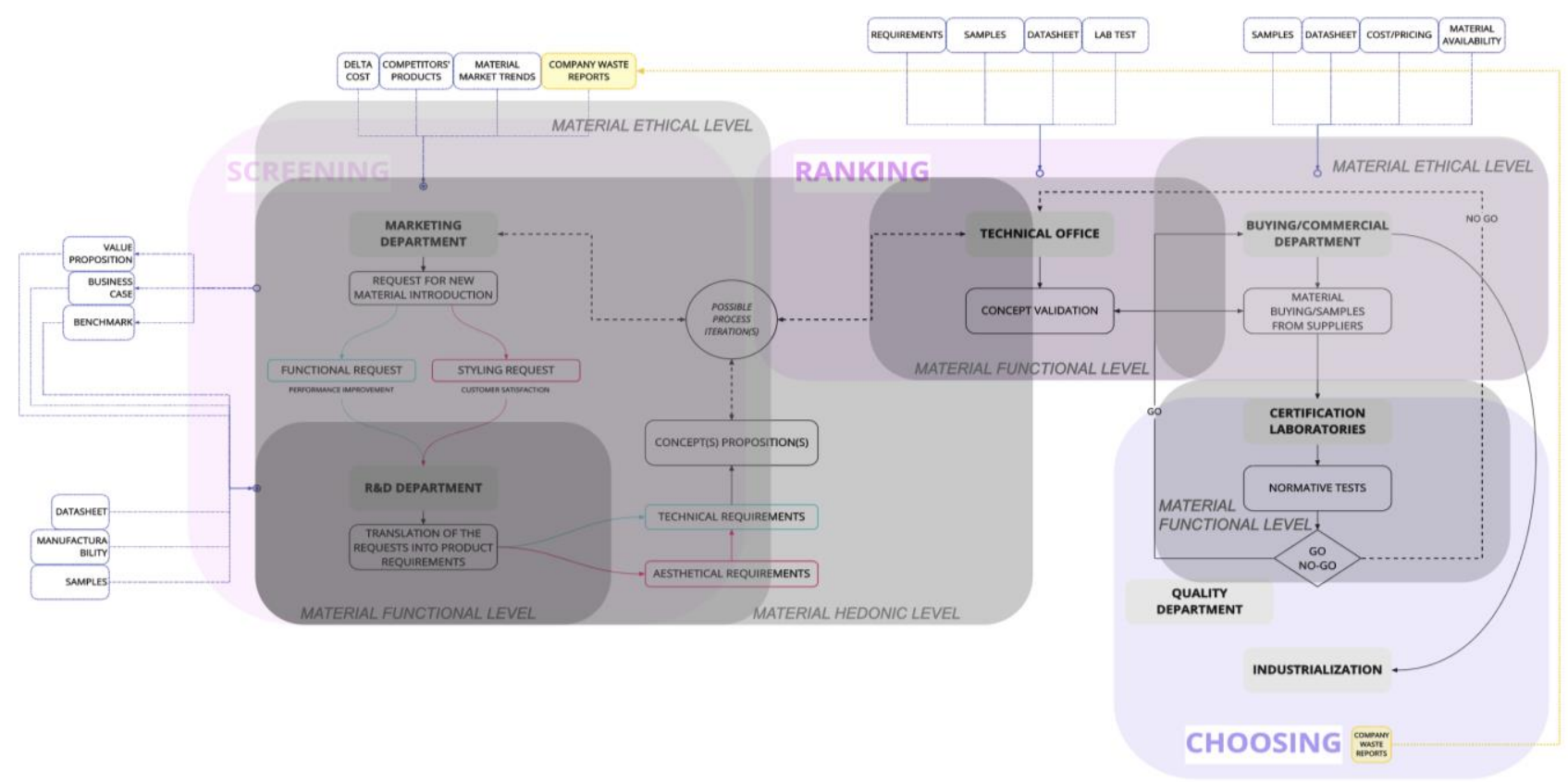

Figure 7. Material information distribution over industrial product design workflow, for visualising the material selection process at systemic level. 
Through the mapping of the different repositories already developed and accessible from the web, all the participant to the workshop were able to find different kind of information upon a selected material, by scouting different sources. In this way, the employees were able to gather and to provide material information to their colleagues and for their own departmental needs.

The main output of the overall research is a framework, in which "standard elements" of the companysystem could be easily recognised (e.g. company departments) and material selection process steps are easily recognisable along the whole product design path, setting the base for theorising a new material selection process solidly based upon cooperation between industrial departments.

In the presented framework, material selection activity is depicted as a cooperative task. Sharing material information between several departments may help in:

- Managing a higher number of information related to the materials;

- Overcoming the resistance to include new materials into the production flow, reducing frustration and optimising time-work;

- Opens to a more fluid integration of innovative materials into the workflow;

- Sets up the basis for having a shared knowledge of the material choices for a specific product.

Future developments of the work, will be focused on creating a specific methodological toolkit to guide the material selection process in the presented systemic perspective. For each stage of the workflow, guided and cooperative activities will be designed in order to define precise procedures to manage material selection process at systemic level.

The role of design in this becomes fundamental due to the importance of visualising the referring scenario. Visual thinking, according to Gaziulusoy and Ryan (2017), becomes a fundamental component in scenarios development towards sustainability transitions. So, further cooperative workshops will exploit visualisations and design research tools (e.g. moodboards and maps), in order to share in the most comprehensive way all the contents and the knowledge that will be produced during the collaborative sessions.

In conclusion, the proposed framework aims to depict how a step-based process as material selection, could be visualised at systemic level. This visualisation helps in enlightening interrelationships between the process and its implications at company-level first and, in future, at wider level. Authors believe that this systemic proposal could help industrial companies in reinforcing their level of resilience in introducing new materials in the workflow, according to environmental demands.

Future works will define in a specific way a possible methodology for pursuing material selection activity in a cooperative way and, consequently, some reflections upon the application of the transferability of the methodology into other industrial contexts will be afforded to ensure the validity of the collaborative material selection process proposal.

\section{REFERENCES}

Akin, F., \& Pedgley, O. (2014). "Sample libraries to expedite materials experience for design: A survey of global provision.” Materials and Design, 90, 1207-1217. https://doi.org/10.1016/j.matdes.2015.04.045

Allione, C., De Giorgi, C., Lerma, B., \& Petruccelli, L. (2012). "From ecodesign products guidelines to materials guidelines for a sustainable product. Qualitative and quantitative multicriteria environmental profile of a material." Energy, 39(1), 90-99. https://doi.org/10.1016/j.energy.2011.08.055

Allwood, J. M., Ashby, M. F., Gutowski, T. G., \& Worrell, E. (2011).” Material efficiency: A white paper.” Resources, Conservation and Recycling, 55(3), 362-381. https://doi.org/10.1016/j.resconrec.2010.11.002

Allwood, J. M., Ashby, M. F., Gutowski, T. G., \& Worrell, E. (2013). "Material efficiency: Providing material services with less material production." Philosophical Transactions of the Royal Society A: Mathematical, Physical and Engineering Sciences, Vol. 371. https://doi.org/10.1098/rsta.2012.0496

Ashby, M. F., \& Bréchet, Y. J. (2003). Designing hybrid materials. Acta materialia, 51(19), 5801-5821.

Ashby, M., Shercliff, H., \& Cebon, D. (2013). "Materials: Engineering, Science, Processing and Design.” 3rd ed. Butterworth-Heinemann

Ashby, M. F., \& Johnson, K. (2014). "Materials and design : the art and science of material selection in product design.” Butterworth-Heinemann.

Bilandzic, M., \& Venable, J. (2011). "Towards Participatory Action Design Research: Adapting Action Research and Design Science Research Methods for Urban Informatics.” The Journal of Community Informatics, $7(3), 1-17$.

Braungart, M., McDonough, W., \& Bollinger, A. (2007). "Cradle-to-cradle design: creating healthy emissions - a strategy for eco-effective product and system design.” Journal of Cleaner Production, 15(13-14), 13371348. https://doi.org/10.1016/j.jclepro.2006.08.003 
Browning, T. R., Deyst, J. J., Eppinger, S. D., \& Whitney, D. E. (2002). Adding value in product development by creating information and reducing risk. IEEE Transactions on Engineering Management, 49(4), 443458. https://doi.org/10.1109/TEM.2002.806710

Brundtland, G. H., Khalid, M., Agnelli, S., Al-Athel, S., \& Chidzero, WCED. (1987). "Our common future." Oxford, New York, 8.

Ceschin, F, Gaziulusoy, I. (2016) "Evolution of design for sustainability: From product design to design for system innovations and transitions", Design Studies, vol.47 pp.118-163

Cornish, E. H. (1987). "Materials and the designer." Cambridge University Press.

Crutzen, P. J., and Stoermer, E. F. (2000), “The International Geosphere-Biosphere Programme (IGBP): A Study of Global Change of the International Council for Science (ICSU)." Global Change Newsletter, 41, $17-18$.

du Gay, P., Smart Martin, A., Miller, T., \& Spyer, P. (1999). Beyond the Pale: Reviewing the Relationship between Material Culture and Design History.Journal of Design History, 12(4), 373-380.

Elkington, J. (1994) Towards the Sustainable Corporation: Win-Win-Win Business Strategies for Sustainable Development. California Management Review, 36, 90-100. http://dx.doi.org/10.2307/41165746

Gaziulusoy, I., Ryan, C. (2017) "Shifting Conversations for Sustainability Transitions Using Participatory Design Visioning”. Design for Next 12th EAD Conference Sapienza University of Rome 12-14 April 2017

Jahan, A., Ismail, M. Y., Sapuan, S. M., \& Mustapha, F. (2010). "Material screening and choosing methods - A review." Materials and Design, 31(2), 696-705. https://doi.org/10.1016/j.matdes.2009.08.013

Jones, P., \& Bowes, J. (2017). "Rendering Systems Visible for Design: Synthesis Maps as Constructivist Design Narratives." She Ji, 3(3), 229-248. https://doi.org/10.1016/j.sheji.2017.12.001

Karana, E., Hekkert, P., \& Kandachar, P. (2008). "Material considerations in product design: A survey on crucial material aspects used by product designers." Materials and Design, 29(6), 1081-1089.

Karana, E., Hekkert, P., \& Kandachar, P. (2010). “A tool for meaning driven materials selection.” Materials \& Design, 31(6), 2932-2941. https://doi.org/10.1016/J.MATDES.2009.12.021

Krishnan, V., \& Ulrich Karl T. (2001). "Product development decisions: a review of the literature." Manag, 47(1), 1-21. Retrieved from http://www.ktulrich.com/uploads/6/1/7/1/6171812/pdreview.pdf

MacArthur Foundation, E. (2017) "What is a Circular Economy?" Ellen MacArthur Foundation.

Manzini, E. (1989). "The material of invention." MIT Press

Pauli, G. (2018). "The Blue Economy:10 years, 100 innovations. 100 Million Jobs.” Paradigm Publications (New Mexico, USA)

Ramalhete, P. S., Senos, A. M. R., \& Aguiar, C. (2010). "Digital tools for material selection in product design." Materials \& Design (1980-2015), 31(5), 2275-2287.

Sevaldson, B. (2011). "Nordic design research conference: GIGA-mapping: Visualisation for complexity and system thinking in design." Nordes, 0(4).

Unger, D., \& Eppinger, S. (2011). "Improving product development process design: A method for managing information flows, risks, and iterations." Journal of Engineering Design, 22(10), 689-699.

Vezzoli, C., Srinivasan, A. (2014), "Product-Service System Design for Sustainability",Green Leaf Publishing Limited.

van Kesteren, I. E. H. (2008). "Product designers' information needs in materials selection.” Materials and Design, 29(1), 133-145. https://doi.org/10.1016/j.matdes.2006.11.008

Wilkes, S., Wongsriruksa, S., Howes, P., Gamester,R., Witchel, H., Conreen, M., Laughlin, Z., Miodownik, M. (2014). "Design tools for interdisciplinary translation of material experiences." Materials and Design. Vol. 90 (2016) 1228-1237

Wilkes, S. E., Miodownik, M. A. (2018). "Materials library collections as tools for interdisciplinary research." Interdisciplinary Science Reviews, 43(1), 3-23. https://doi.org/10.1080/03080188.2018.1435450 


\section{APPENDIX}

Results from the systematic mapping of materials information repositories.

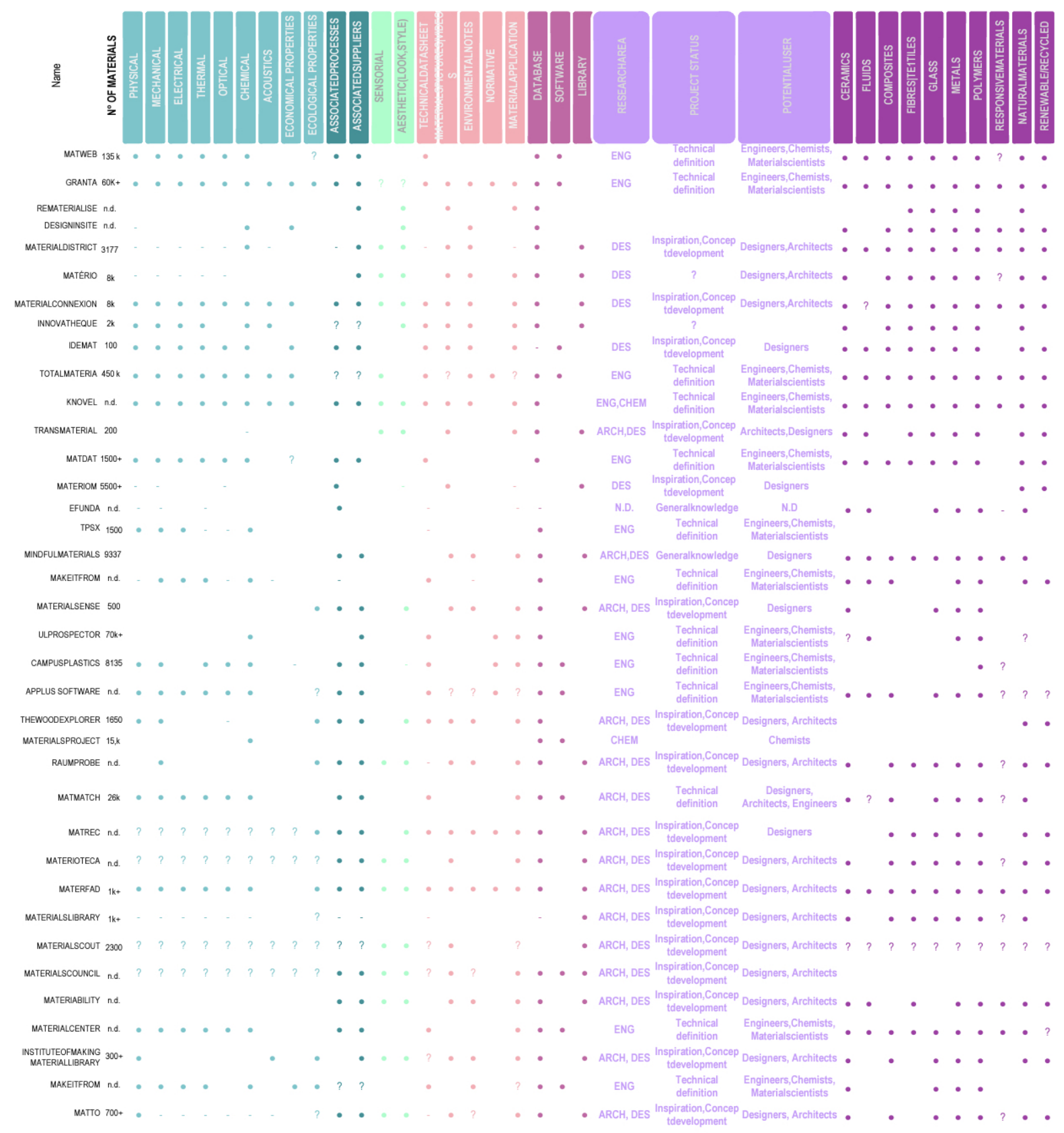

